\title{
Assessment of the effect of addition of 24 hours of oral tranexamic acid post- operatively to a single intraoperative intravenous dose of tranexamic acid on calculated blood loss following primary hip and knee arthroplasty (TRAC-24): a study protocol for a randomised controlled trial
}

Janet Hill ${ }^{*}$ (D, Paul Magill', Alastair Dorman², Rosemary Hogg ${ }^{2}$, Andrew Eggleton ${ }^{3}$, Gary Benson ${ }^{4}$, Margaret McFarland ${ }^{5}$, Lynn Murphy ${ }^{6}$, Evie Gardner ${ }^{6}$, Leeann Bryce ${ }^{1}$, Una Martin ${ }^{1}$, Catherine Adams ${ }^{6}$, Jennifer Bell, Christina Campbell ${ }^{6}$, Ashley Agus ${ }^{6}$, Glenn Phair ${ }^{6}$, Dennis Molloy ${ }^{1}$, Brian Mockford ${ }^{1}$, Seamus O'Hagan ${ }^{1}$ and David Beverland ${ }^{1}$

\begin{abstract}
Background: While it is has been proven that tranexamic acid (TXA) reduces blood loss in primary total hip and knee arthroplasty (THA and TKA), there is little published evidence on the use of TXA beyond $3 \mathrm{~h}$ post-operatively. Most blood loss occurs after wound closure and the primary aim of this study is to determine if the use of oral TXA post-operatively for up to $24 \mathrm{~h}$ will reduce calculated blood loss at $48 \mathrm{~h}$ beyond an intra-operative intravenous bolus alone following primary THA and TKA. To date, most TXA studies have excluded patients with a history of thromboembolic disease.

Methods/design: This is a phase IV, single-centred, open-label, parallel-group, randomised controlled trial. Participants are randomised to one of three groups: group 1, an intravenous (IV) bolus of TXA peri-operatively plus oral TXA post-operatively for 24 h; group 2, an IV bolus of TXA peri-operatively or group 3, standard care (no TXA). Eligible participants, including those with a history of thromboembolic disease, are allocated to these groups with a 2:2:1 allocation ratio. The primary outcome is the indirectly calculated blood loss $48 \mathrm{~h}$ after surgery. Researchers and patients are not blinded to the treatment; however, staff processing blood samples are. Originally 1166 participants were required to complete this study, 583 THA and 583 TKA. However, following an interim analysis after 100 THA and 100 TKA participants had been recruited to the study, the data monitoring ethics committee recommended stopping group 3 (standard care).
\end{abstract}

(Continued on next page)

\footnotetext{
* Correspondence: janet.hill@belfasttrust.hscni.net

${ }^{1}$ Primary Joint Unit, Musgrave Park Hospital, Belfast Health and Social Care

Trust, Stockman's Lane, Belfast BT9 7JB, UK

Full list of author information is available at the end of the article
}

(c) The Author(s). 2018 Open Access This article is distributed under the terms of the Creative Commons Attribution 4.0 International License (http://creativecommons.org/licenses/by/4.0/), which permits unrestricted use, distribution, and reproduction in any medium, provided you give appropriate credit to the original author(s) and the source, provide a link to the Creative Commons license, and indicate if changes were made. The Creative Commons Public Domain Dedication waiver (http://creativecommons.org/publicdomain/zero/1.0/) applies to the data made available in this article, unless otherwise stated. 
(Continued from previous page)

Discussion: TRAC-24 will help to determine whether an extended TXA dosing regimen can further reduce blood loss following primary THA and TKA. By including patients with a history of thromboembolic disease, this study will add to our understanding of the safety profile of TXA in this clinical situation.

Trial registration: ISRCTN registry, ISRCTN58790500. Registered on 3 June 2016, EudraCT: 2015-002661-36.

Keywords: Tranexamic acid, Blood loss, Hip, Knee, Arthroplasty, Replacement, Post-operative, Oral,

\section{Background}

Increased peri-operative and post-operative blood loss following total hip arthroplasty (THA) and total knee arthroplasty (TKA) can significantly influence the morbidity and mortality for both procedures [1]. Expected blood loss in these operations can range between 500 and $1600 \mathrm{~mL}[2,3]$. The resulting anaemia increases a patient's risk of cardiovascular and respiratory complications, increases infection rates and impedes functional mobility.

Tranexamic acid (TXA) is well established in many areas of medicine for reducing blood loss [4] and is a mainstay in the management of traumatic haemorrhage in the emergency department $[5,6]$. In lower limb arthroplasty, two meta-analyses of randomised controlled trials using TXA in THA and TKA concluded in favour of its use to limit blood loss $[7,8]$. TXA in elective arthroplasty is not yet supported by the National Institute for Health and Care Excellence or British Orthopaedic Association guidelines. In part, this is because, despite a lack of published evidence, there are theoretical concerns about the potential increased risk of venous thromboembolism (VTE) with TXA [9]. Other countries, such as the USA, have embraced the use of TXA in arthroplasty [10-12], favouring the proven benefit of reduced blood loss in these typically elderly patients over the theoretical risk of VTE. To date, there have been no published safety concerns with this approach. A further issue with widespread TXA adoption is the absence of an established standard treatment regime in elective joint arthroplasty. As such, published studies describe a range of doses, routes of administration and durations of treatment [13-17].

Since the study protocol was first authorised for this trial in 2015, a wealth of studies has been published on TXA use in THA and TKA further advocating its use. However, determination of the most effective duration of TXA treatment, dosage and regimen for major joint arthroplasty has barely been investigated. Most studies focus on the intra-operative period [18, 19] with little published work into treatment regimes that extend beyond a dose $3 \mathrm{~h}$ post-operatively. However, we postulate that the period of greatest importance is the first 24 post-operative hours. This theory is based upon an internal audit carried out at Musgrave Park Hospital, Belfast, Northern Ireland, on 361 consecutive patients undergoing THA. We compared patients' intra-operative blood loss to their total blood loss at 2 days post-operatively. Total blood loss was calculated indirectly using equations based on a change in haematocrit $[20,21]$. The average directly measured intra-operative blood loss was $223 \mathrm{~mL}$ (range 50-1204 mL) and the average indirectly calculated total blood loss was $1377 \mathrm{~mL}$ (range 263-3864 mL). On average, the total loss was over six times the measured loss in theatre. Other relevant findings from this audit were that on average $90 \%$ of total loss occurs in the first 24 post-operative hours and that intra-operative blood loss grossly underestimates total blood loss, thus making it a poor predictor of total loss. Based on this audit and other literature demonstrating that blood loss continues in the first $24 \mathrm{~h}$ post-operatively [22-26], we hypothesise that using TXA up to $24 \mathrm{~h}$ post-operatively has the potential to reduce blood loss further following THA and TKA, compared to a single peri-operative dose of TXA. Since there is evidence that oral administration is equally efficacious as intravenous administration [27, 28], this study uses oral TXA post-operatively as a cheaper and less labour-intensive mode of delivery than either IV bolus or infusion regimes.

TRAC-24 will help to define the optimum treatment protocol for TXA use for peri-operative blood loss management in lower limb arthroplasty and will inform the standard of care both at the study site and elsewhere in relation to the use of peri-operative TXA. TRAC-24 will also contribute to the evidence base regarding TXA use and the risk of peri-operative venous and arterial thromboembolism. However, to determine definitively what impact TXA has on VTE in the peri-operative period, a larger-scale multi-centre study would be required.

\section{Objectives}

The primary objective is to determine if the use of oral TXA post-operatively for up to $24 \mathrm{~h}$ will confer a reduction in calculated blood loss at $48 \mathrm{~h}$ beyond an intra-operative intravenous bolus alone for patients undergoing unilateral primary THA or TKA.

The secondary objective is to determine if the addition of oral TXA post-operatively to an intra-operative intravenous bolus of TXA produces any change in other measurable parameters compared to those observed for either an intra-operative intravenous bolus alone or no TXA for patients undergoing unilateral primary THA or TKA. 


\section{Methods/design}

\section{Study design}

This is a phase IV, single-centred, open-label, parallel-group, randomised controlled trial assessing superiority. Elective primary THA and TKA patients are allocated to either one of two TXA intervention groups or one non-treatment comparator group. A study flowchart is shown in Fig. 1. The protocol was written in accordance with the Standard Protocol Items: Recommendations for Interventional Trials (SPIRIT). A SPIRIT figure can be seen in Fig. 2. The SPIRIT checklist is given in Additional file 1 .

When the study was initially planned, the peri-operative use of TXA was not a standard of care in primary THA and TKA in the UK and local site policy reserved its use for patients considered at high bleeding risk. Therefore, the no-intervention control group was deemed necessary to reflect current practice. However, following an interim analysis and review of safety data, which was performed as part of a scheduled data monitoring and ethics committee (DMEC) meeting, it was recommended that randomisation to control group 3 be discontinued. This DMEC meeting took place after 200 participants (40 of whom were in control group 3) had been recruited. By the time approval was gained for this protocol change, 134 participants had been recruited to the control group.

\section{Primary outcome measure}

The primary outcome measure is the total calculated volume of blood loss, in millilitres, at $48 \mathrm{~h}$. This is calculated indirectly, from a series of equations [20, 21, 29].

The first equation determines the patient's blood volume in litres:

$$
\mathrm{PBV}=\left(k_{1} \times h^{3}\right)+\left(k_{2} \times w\right)+k_{3}
$$

where

$\mathrm{PBV}=$ patient's blood volume $(\mathrm{L})$,

$h=$ height $(\mathrm{m})$,

$w=$ weight $(\mathrm{kg})$,

$k_{1}=0.3669$ for men and 0.3561 for women,

$k_{2}=0.03219$ for men and 0.03308 for women

and

$k_{3}=0.6041$ for men and 0.1833 for women.

The second equation determines the volume of red blood cells lost in the period from immediately before the operation to 48 -h post operatively. Note that PBV should be converted to millilitres prior to calculation of $\mathrm{RBC}$.

$$
\mathrm{RBC}=\mathrm{PBV} \times\left(\mathrm{Hct}_{\text {pre-op }}-\mathrm{Hct}_{\text {post-op } 48 \mathrm{~h}}\right),
$$

where

$\mathrm{RBC}=$ red blood cell volume loss $(\mathrm{mL})$,

Hct $_{\text {pre-op }}=$ pre-operative haematocrit

and
Hct $_{\text {post-op } 48 \mathrm{~h}}=$ post-operative haematocrit.

The third and final equation converts red cell volume loss into whole blood volume loss. We selected the Gross formula for this [29] and adapted it to incorporate transfusions as per the Mercuriali formula [21].

To convert red blood cell volume loss into total blood volume loss, the RBC must be divided by the average Hct. In addition, volume of transfused blood must be taken into account. An average unit of blood has a volume of $280 \mathrm{ml}$ with an Hct of 0.6 , which is the red cell equivalent of $168 \mathrm{mls}$ with an Hct of 1.0 . As this is diluted by patient blood volume, the value must again be divided by average Hct.

The Gross formula (adapted assuming an average Packed Red Cells (PRC) unit is $280 \mathrm{~mL}$ with a Hct of 0.6) is

$$
\begin{aligned}
& \text { Total volume loss }=\frac{\mathrm{RBC}}{\mathrm{Hct}_{\mathrm{avg}}} \\
& +\left((\text { No units PRCs } \times 168) / \mathrm{Hct}_{\mathrm{avg}}\right),
\end{aligned}
$$

where

$$
\mathrm{Hct}_{\mathrm{avg}}=\frac{\left(\text { Hct }_{\text {pre-op }}+\text { Hct }_{\text {post-op48h }}\right)}{2} .
$$

The resultant total volume loss is the primary outcome measure. Traditionally, the primary outcome measure in TXA studies has been transfusion rate. The incidence of transfusion at the study site for TKA patients reduced from $76.0 \%$ in 2001 to $5.8 \%$ in 2013 . This fall preceded TXA use and was a consequence of a more restrictive transfusion policy. Consequently, because transfusion rates are now relatively low, transfusion was not considered to be the most relevant primary outcome measure. As the primary outcome measure, total volume loss is independent of clinician or investigator bias, effectively becoming a blinded outcome measure. Transfusion is more vulnerable to bias because although a transfusion trigger is set prior to surgery, it is simply a prompt for clinicians to consider transfusion and not necessarily to transfuse. Essentially fit patients $<65$ years have a trigger of $<70 \mathrm{~g} / \mathrm{L}$ and those $>65$ a trigger of $<80 \mathrm{~g} / \mathrm{L}$. All those with potential risk factors have a trigger of $<90 \mathrm{~g} / \mathrm{L}$ and symptomatic patients a trigger of $<10 \mathrm{~g} / \mathrm{L}$.

The study also has a number of secondary and exploratory outcomes. The secondary outcomes characterise other benefits of the interventions for patients undergoing primary THA or TKA. Exploratory outcome measures will not be evaluated to the same extent as the primary and secondary outcomes but have the potential to generate future studies.

Secondary outcome measures

The secondary outcomes are: 


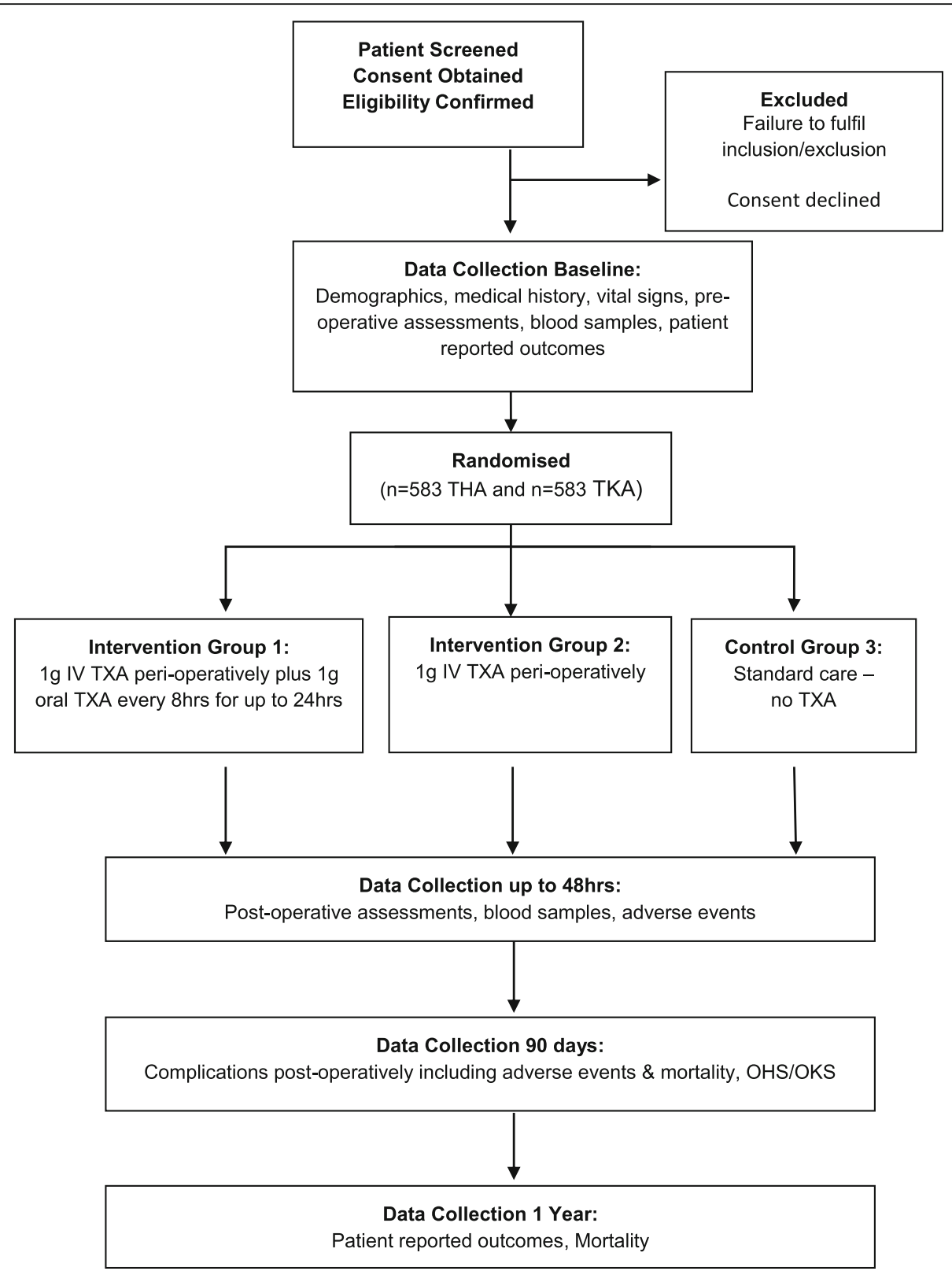

Fig. 1 Flowchart for study participants. IV intravenous, OHS Oxford hip score, OKS Oxford knee score, Op operative, TXA tranexamic acid

- Incidence of post-operative haemoglobin $(\mathrm{Hb})$ falling below the transfusion trigger (irrespective of transfusion) prior to discharge

- Effect of body mass index on the volume of indirect blood loss at $48 \mathrm{~h}$ post-surgery

- Change in C-reactive protein (CRP) level from pre-operative to $48 \mathrm{~h}$ post-operative

- Change in creatinine level from pre-operative to $48 \mathrm{~h}$ post-operative

- 90-day mortality

- year mortality

\section{Exploratory outcome measures}

Exploratory outcomes include:

- Comparison of intra-operative blood loss between the groups

- Number of wound dressing changes in the first $48 \mathrm{~h}$ post-operatively

- Requests (and results) for post-operative troponin levels prior to discharge

- Post-operative length of hospital stay

- Incidence of allogenic blood transfusion prior to discharge 


\begin{tabular}{|c|c|c|c|c|c|c|c|c|c|c|c|}
\hline TIMEPOINTS & 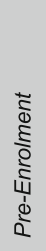 & 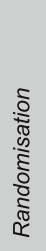 & 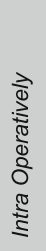 & $\begin{array}{l}\delta \\
\text { बे } \\
\text { वे }\end{array}$ & $\vec{\nabla}$ & $\begin{array}{l}N \\
\vec{\Phi} \\
\stackrel{0}{0}\end{array}$ & $\stackrel{m}{\overparen{\Phi}}$ & $\underset{\stackrel{\nabla}{\sigma}}{+}$ & 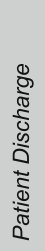 & $\begin{array}{l}\text { Follow } \\
\overrightarrow{0} \\
0 \\
8 \\
\overrightarrow{8} \\
\stackrel{0}{0}\end{array}$ & 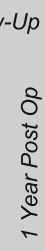 \\
\hline $\begin{array}{l}\text { ENROLMENT: } \\
\text { Eligibility screen } \\
\text { Informed Consent } \\
\text { Patient Demographics } \\
\text { Randomisation } \\
\text { Treatment Group Allocation }\end{array}$ & $\begin{array}{l}X \\
X\end{array}$ & $\begin{array}{l}x \\
x \\
x\end{array}$ & & & & & & & & & \\
\hline $\begin{array}{l}\text { INTERVENTIONS: } \\
\text { Group 1: Intervention - IV TXA \& Oral TXA* } \\
\text { Group 2: Intervention - IV TXA Only } \\
\text { Group 3: Control - Standard Care }\end{array}$ & & & $x$ & & & & & & & & \\
\hline $\begin{array}{l}\text { PRE-OPERATIVE ASSESSMENTS: } \\
\text { Physical Examination } \\
\text { Medical History } \\
\text { Medication History } \\
\text { OHS/OKS } \\
\text { Pre-Op Bloods }{ }^{\#}\end{array}$ & & $\begin{array}{l}x \\
x \\
x \\
x \\
x\end{array}$ & & & & & & & & & \\
\hline $\begin{array}{l}\text { INTRA-OPERATIVELY } \\
\text { Operation Details }{ }^{\ddagger} \\
\text { Intra-Op Transfusions }\end{array}$ & & & $\begin{array}{l}x \\
x\end{array}$ & & & & & & & & \\
\hline $\begin{array}{l}\text { POST OPERATIVELY: } \\
\text { Study Drug Admin } \\
\text { Post-Op Bloods } \\
\text { Post-Op Transfusions } \\
\text { Dressing Changes }\end{array}$ & & & & $\begin{array}{l}x \\
x \\
x \\
x\end{array}$ & $\begin{array}{l}x \\
x \\
x \\
x\end{array}$ & $\begin{array}{l}x \\
x \\
x \\
x\end{array}$ & $\begin{array}{l}x \\
x \\
x\end{array}$ & $\begin{array}{l}x \\
x \\
x\end{array}$ & & & \\
\hline $\begin{array}{l}\text { PATIENT DISCHARGE: } \\
\text { Inpatient Medical History } \\
\text { Transfusions History } \\
\text { Admission Pathway } \\
\text { Patient Discharge }\end{array}$ & & & & & & & & & $\begin{array}{l}x \\
x \\
x \\
x\end{array}$ & & \\
\hline $\begin{array}{l}\text { PATIENT FOLLOW-UP: } \\
\text { Hospital Readmission } \\
\text { Additional Radiology } \\
\text { Medical History } \\
\text { OHS/OKS } \\
\text { Patient Survival Status } \\
\text { Adverse Events }\end{array}$ & & & & & & & & & & $\begin{array}{l}x \\
x \\
x \\
x \\
x \\
x\end{array}$ & $\begin{array}{l}x \\
x\end{array}$ \\
\hline $\begin{array}{l}\text { OUTCOMES: } \\
\text { Indirect Blood Loss 48hrs Post-Op } \\
\text { Effect of BMI on indirect blood loss } \\
\text { Post Op Complications (Days 0-90) } \\
\text { Outcome Scores } \\
\text { Incidence of Hb falling below transfusion } \\
\text { trigger before discharge } \\
\text { Change in CRP (pre-op \& 48hr post-op) } \\
\text { Change in Creatinine (pre-op \& 48hr post-op) } \\
\text { Mortality }\end{array}$ & & & & $x$ & $\mathrm{x}$ & $\begin{array}{l}X \\
X\end{array}$ & $\mathrm{X}$ & $x$ & $x$ & 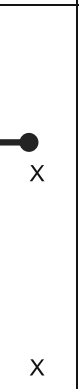 & $x$ \\
\hline
\end{tabular}

Fig. 2 Schedule of enrolment, intervention and assessments. CRP C-reactive protein, Hb haemoglobin, Hct haematocrit, IV intravenous, INR International normalised ratio, KTS knife to skin, OHS Oxford hip score, OKS Oxford knee score, TXA tranexamic acid 
- Incidence of allogenic blood transfusion within 90 days of surgery

- Incidence of post-operative $\mathrm{Hb}$ falling below the transfusion trigger without the patient being transfused to time of discharge

- Incidence of post-operative arrhythmia within 90 days of surgery

- Incidence of s within 90 days of surgery

- Incidence of proximal deep vein thrombosis within 90 days of surgery

- Incidence of myocardial infarction within 90 days of surgery

- Incidence of cerebrovascular accidents within 90 days of surgery

- Emergency hospital admission or unplanned critical care admission within 90 days of surgery

- Number of returns to theatre for wound problems within 90 days of surgery

- Difference in indirect blood loss at $48 \mathrm{~h}$ between patients on aspirin as a VTE prophylaxis compared with those on enoxaparin

- Difference in indirect blood loss at $48 \mathrm{~h}$ between patients placed in flexion in a knee jig for $6 \mathrm{~h}$ post-operatively as opposed to those placed in flexion on a pillow

- Difference in indirect blood loss at $48 \mathrm{~h}$ between patients for whom a tourniquet was used compared to those for whom a tourniquet was not used during TKA

- Change in Oxford hip score (OHS) or Oxford knee score (OKS) from pre-operatively to 90 days post-operatively

- Change in OHS or OKS from pre-surgery to 1-year post-surgery

- Differences in hospital costs associated with each treatment group

The OHS and OKS are outcome measures [30] widely used pre- and post-operatively for all patients at the study site to measure the success of an operation. It will be important to ensure that there are no differences in OHS/OKS at 1 year between each of the groups. The OKS/OHS is assessed for patients by hospital staff at their pre-operative assessment clinic, at the 90 day follow-up review clinic (for TKA patients only) and at the patient's 1-year clinic as part of standard care. Patients must attend their pre-operative assessment clinic, but should any patient be unable to attend a post-operative clinic, the OHS/OKS will be completed via telephone. THA patients have an early post-operative clinic at 6 weeks routinely, so for this study the 90-day OHS is assessed over the telephone by research nurses. Because the participants are not blinded to their intervention, there is the potential for bias when completing the Oxford scores at 90 days and 1 year following surgery. Practically, we feel any such effect would be negligible.

The incidence of death and complications at 90-days post-operatively are clinically important outcomes for this study. While this study is not powered to answer whether the use of TXA can lower complications, it is important that complications are reported.

\section{Study setting}

This is a single-centre study taking place in a Primary Joint Unit in a regional orthopaedic centre in the UK with patients under the care of one of four consultant orthopaedic surgeons being recruited to the study.

\section{Study participants}

Participants who are on the waiting list for a primary THA or TKA within the Primary Joint Unit are screened for study inclusion.

\section{Inclusion criteria}

The following inclusion applies:

- Awaiting primary elective THA or TKA

- $\geq 18$ years and $\leq 100$ years of age

\section{Exclusion criteria}

The exclusion criteria for this trial are:

- Do not pass a pre-operative assessment for elective THA or TKA

- Fractured neck of femur

- Haemophiliac or coagulation disorders that require TXA

- Allergy to TXA or any of its excipients

- Platelets less than $75,000 / \mathrm{mm}^{3}$ at pre-operative assessment*

- Active treatment for deep VTE or pulmonary embolism within 6 months prior to surgery*

- History of VTE within 6 months prior to surgery*

- Myocardial infarction within 12 months prior to surgery"

- Cardiac stent within 12 months prior to surgery*

- Cerebrovascular accident or transient ischemic attack within 9 months prior to surgery*

- Use of antiplatelet medication within 7 days prior to surgery" (does not include aspirin if dose $<300 \mathrm{mg}$ ).

- Direct thrombin inhibitors within 2 days prior to surgery"

- Factor Xa inhibitors within 2 days prior to surgery*

- The international normalised ratio is greater than or equal to 1.5 in a patient who has stopped warfarin in preparation for surgery

- Hepatic failure*

- History of epilepsy

- Requiring therapeutic anticoagulation postoperatively, e.g. due to a metallic heart valve 
- Pregnant women, women who have not yet reached the menopause (no menses for $\geq 12$ months without an alternative medical cause) who test positive for pregnancy or are unwilling to take a pregnancy test prior to trial entry

- Have been using combined hormonal contraception (which includes combined oral contraception, a combined contraceptive transdermal patch and a vaginal ring) within 4 weeks prior to surgery*

- Female patients who are breastfeeding

- Treated with any other investigational medication or device within 60 days prior to surgery

- Unable to provide informed consent

- Unable or unwilling to commit to the study schedule of events

- Unwilling to provide informed consent

- Present for simultaneous bilateral THA or TKA

- On renal dialysis and have an arteriovenous fistula

- Have previously been enrolled in this study

*These patients at the study site have contra-indications to primary THA/TKA.

\section{Recruitment and consent}

TRAC-24 originally required a minimum of 1166 patients to be recruited. Recruitment would stop when 583 participants were recruited for both TKA and THA. However, following a DMEC recommendation, recruitment to control group 3 was stopped, after approval from the sponsor, the regional ethics committee and the Medicines and Healthcare Products Regulatory Agency (MHRA) was acquired. At this point, 672 participants had been recruited to the study. This meant that a minimum of 466 THA and 466 TKA were now required to complete the study with a minimum overall recruitment of 1066, recruiting only to groups 1 and 2. Potentially eligible patients are identified and screened by members of the clinical study team based on the inclusion and exclusion criteria outlined above.

A cover letter and a patient information sheet approved by the Research Ethics Committee is sent to potential patients informing them about the study. The latter contains a contact number should they have any questions or wish to discuss the study further. The study is then discussed directly with the patient at a pre-operative clinic (approximately 7 to 10 days prior to operation) or following admission for surgery. Informed consent is taken by a member of the research team after the participant has been given the opportunity to ask further questions and agrees to participate.

\section{Study assessments}

All patients are evaluated during the study according to the schedule of enrolment, interventions and assessments as outlined in Fig. 2. Data are collected at each of the following time points: pre-operatively, intra-operatively, post-operatively until discharge and then at 90 days and 1 year post-operatively.

\section{Randomisation and blinding procedures}

At the outset of the trial, eligible participants were allocated to intervention group 1, intervention group 2 or control group 3 (standard care) with an allocation ratio of 2:2:1. After the DMEC recommended stopping randomisation to control group 3, eligible participants were then allocated to intervention group 1 or intervention group 2 with an allocation ratio of 1:1. Blocked randomisation with randomly permuted block sizes is used. Participants are stratified according to operation type, surgeon and creatinine level, resulting in 16 possible stratifications (Fig. 3):

The randomisation sequence is concealed using sealed envelopes with tamper-proof labels. The trial statistician generated the randomisation sequence. When a participant has been recruited, consented and admitted to the ward pre-operatively, a sealed envelope is opened in sequence according to the stratification. Two members of the research team must be present for this. The envelope is not opened until the post-operative transfusion trigger has been recorded, which is set after consent and prior to randomisation. Anaesthetists, surgeons, and other theatre, recovery and ward staff will not be blinded to the treatment, nor will the study investigators or the patient themselves. The decision to transfuse is not blinded but the transfusion trigger is blinded. This means that the number of patients falling below that transfusion trigger is blinded. Laboratory staff who process the blood samples are blinded to the treatment allocation.

\section{Interventions}

For intervention group 1, intra-operative intravenous TXA is administered within 30 min before knife to skin (KTS) or application of a tourniquet plus oral TXA at $2 \mathrm{~h}, 10 \mathrm{~h}, 18 \mathrm{~h}$ and $26 \mathrm{~h}$ post KTS. Each oral dose should be given within a $2 \mathrm{~h}$ window but not earlier than the planned time point for the first dose. Patients with renal impairment will receive a reduced dose dependent on their pre-operative serum creatinine as per Table 1.

For intervention group 2, intra-operative intravenous TXA is administered within 30 min before KTS or application of a tourniquet. Patients with renal impairment will receive a reduced dose dependent on their pre-operative serum creatinine.

\section{Study drug}

TXA $100 \mathrm{mg} / \mathrm{mL}$ solution for injection and TXA $500 \mathrm{mg}$ tablets are regarded as investigational medicinal products for this study. 


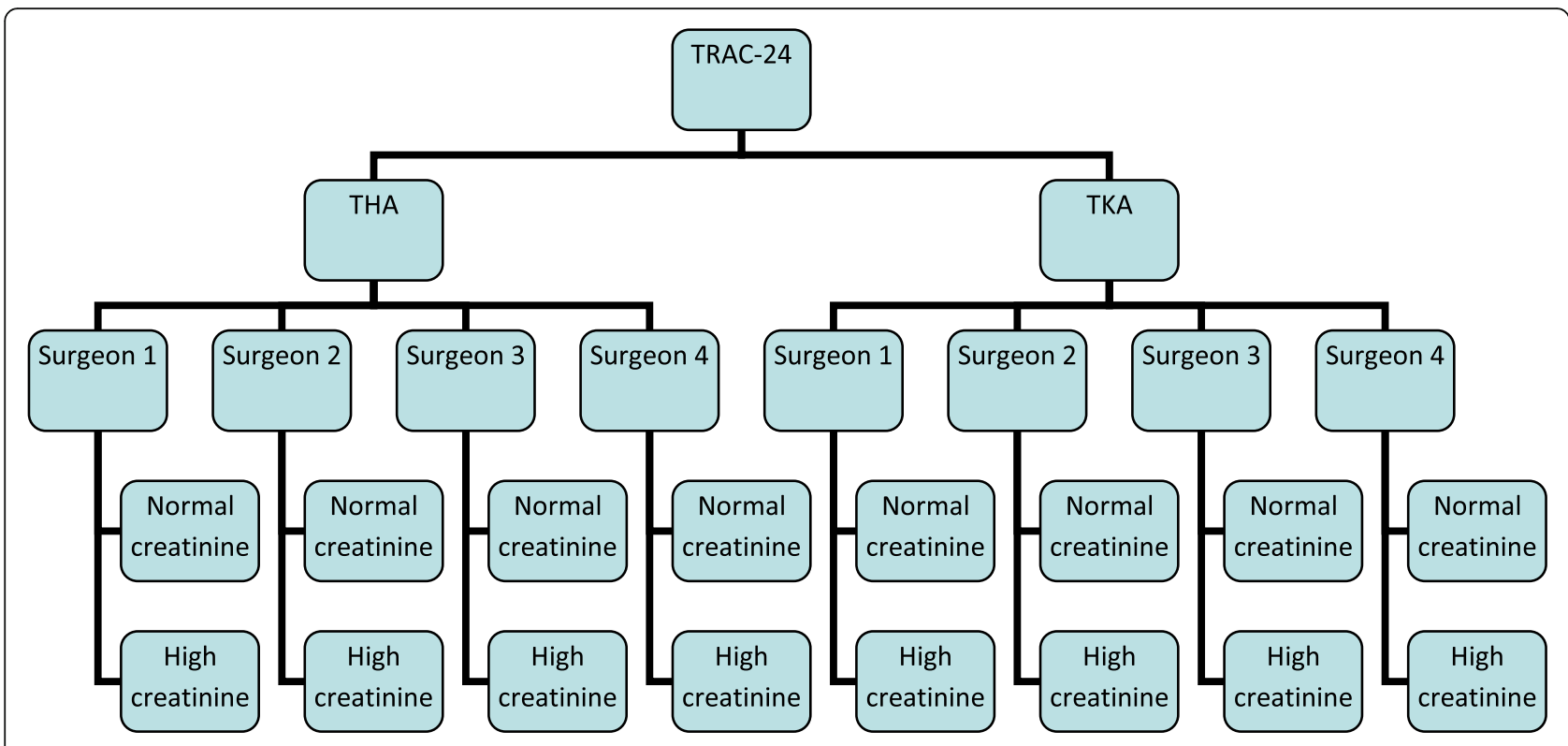

Fig. 3 Stratification factors. THA total hip arthroplasty, TKA total knee arthroplasty

The study medication is provided as:

- Packs containing two 5-mL ampoules of TXA $100 \mathrm{mg} / \mathrm{mL}$ solution for injection

- Packs containing one 5-mL ampoule of TXA $100 \mathrm{mg} / \mathrm{mL}$ solution for injection (for patients with renal impairment)

- Packs containing eight TXA 500 mg tablets
- Packs containing four tablets, two tablets or one tablet TXA $500 \mathrm{mg}$ (for patients with renal impairment)

Packs are labelled with a unique medication pack identification number in accordance with applicable regulatory requirements. On receipt of a study medication request form, signed by an authorised member of the research

Table 1 Study drug administration

\begin{tabular}{|c|c|c|c|c|c|}
\hline & $\begin{array}{l}\text { Up to } 30 \text { mins } \\
\text { pre KTS }\end{array}$ & $\begin{array}{l}+2 \mathrm{~h} \\
\text { post KTS }\end{array}$ & $\begin{array}{l}+10 \mathrm{~h} \\
\text { post KTS }\end{array}$ & $\begin{array}{l}+18 \mathrm{~h} \\
\text { post KTS }\end{array}$ & $\begin{array}{l}+26 \mathrm{~h} \\
\text { post KTS }\end{array}$ \\
\hline $\begin{array}{l}\text { Intervention group } 1 \\
\text { Normal creatinine }<120 \mu \mathrm{mol} / \mathrm{L}\end{array}$ & $\begin{array}{l}1 \mathrm{~g} \\
\text { TXA IV }\end{array}$ & $\begin{array}{l}1 \mathrm{~g} \\
\text { TXA oral }\end{array}$ & $\begin{array}{l}1 \mathrm{~g} \\
\text { TXA oral }\end{array}$ & $\begin{array}{l}1 \mathrm{~g} \\
\text { TXA oral }\end{array}$ & $\begin{array}{l}1 \mathrm{~g} \\
\text { TXA oral }\end{array}$ \\
\hline $\begin{array}{l}\text { Intervention group } 1 \\
\text { High (A) creatinine level } 120-249 \mu \mathrm{mol} / \mathrm{L}\end{array}$ & $\begin{array}{l}0.5 \mathrm{~g} \\
\text { TXA IV }\end{array}$ & $\begin{array}{l}0.5 \mathrm{~g} \\
\text { TXA oral }\end{array}$ & $\begin{array}{l}0.5 \mathrm{~g} \\
\text { TXA oral }\end{array}$ & $\begin{array}{l}0.5 \mathrm{~g} \\
\text { TXA oral }\end{array}$ & $\begin{array}{l}0.5 \mathrm{~g} \\
\text { TXA oral }\end{array}$ \\
\hline $\begin{array}{l}\text { Intervention group } 1 \\
\text { High (B) creatinine level } 250-499 \mu \mathrm{mol} / \mathrm{L}\end{array}$ & $\begin{array}{l}0.5 \mathrm{~g} \\
\text { TXA IV }\end{array}$ & - & $\begin{array}{l}0.5 \mathrm{~g} \\
\text { TXA oral }\end{array}$ & - & $\begin{array}{l}0.5 \mathrm{~g} \\
\text { TXA oral }\end{array}$ \\
\hline $\begin{array}{l}\text { Intervention group } 1 \\
\text { High (C) creatinine level } \geq 500 \mu \mathrm{mol} / \mathrm{L}\end{array}$ & $\begin{array}{l}0.5 \mathrm{~g} \\
\text { TXA IV }\end{array}$ & - & - & - & $\begin{array}{l}0.5 \mathrm{~g} \\
\text { TXA oral }\end{array}$ \\
\hline $\begin{array}{l}\text { Intervention group } 2 \\
\text { Normal creatinine level }<120 \mu \mathrm{mol} / \mathrm{L}\end{array}$ & $\begin{array}{l}1 \mathrm{~g} \\
\text { TXA IV }\end{array}$ & - & - & - & - \\
\hline $\begin{array}{l}\text { Intervention group } 2 \\
\text { High (A) creatinine level } 120-249 \mu \mathrm{mol} / \mathrm{L}\end{array}$ & $\begin{array}{l}0.5 \mathrm{~g} \\
\text { TXA IV }\end{array}$ & - & - & - & - \\
\hline $\begin{array}{l}\text { Intervention group } 2 \\
\text { High (B) creatinine level } 250-499 \mu \mathrm{mol} / \mathrm{L}\end{array}$ & $\begin{array}{l}0.5 \mathrm{~g} \\
\text { TXA IV }\end{array}$ & - & - & - & - \\
\hline $\begin{array}{l}\text { Intervention group } 2 \\
\text { High }(C) \text { creatinine level } \geq 500 \mu \mathrm{mol} / \mathrm{L}\end{array}$ & $\begin{array}{l}0.5 \mathrm{~g} \\
\text { TXA IV }\end{array}$ & - & - & - & - \\
\hline $\begin{array}{l}\text { Control group } 3 \text { - no TXA } \\
\text { All creatinine levels }\end{array}$ & - & - & - & - & - \\
\hline
\end{tabular}


team, the pharmacy department supplies a number of medication packs to the operating theatre. These are then available for administration to patients according to the treatment allocation specified in the assigned sealed envelope. The medication pack goes with the patient from theatre to ward depending on randomisation.

Drug administration is recorded on the patient's hospital prescription chart and on their case report form (CRF).

Used and unused medication packs are returned to the site pharmacy department. The site pharmacist is responsible for maintaining complete records of the disposition of all study drugs that are received, dispensed, unused, expired, returned to pharmacy or destroyed. The Northern Ireland Clinical Trials Unit (NICTU) provides a drug accountability record form for this purpose. All investigational medicinal products for this study are sourced, packed and labelled for the trial by Victoria Pharmaceuticals, Belfast Health and Social Care Trust.

TXA is administered by slow intravenous injection or orally at the time points indicated in Table 1 in accordance with the treatment allocation specified in the assigned sealed envelope. There are no relevant concomitant care and interventions that are permitted or prohibited during the trial.

\section{Safety}

The conduct of the trial is overseen by a trial steering committee (TSC). Throughout the trial, the TSC takes responsibility for monitoring and guiding overall progress, scientific standards, operational delivery and protecting the rights and safety of trial patients. Monthly trial management group meetings are held involving the NICTU and members of the research team. An independent DMEC was appointed with responsibility for safeguarding the interests of trial patients. This committee monitors the main outcome measures including safety and efficacy. It also assists and advises the TSC to protect the validity and credibility of the trial. Charters for the TSC, DMEC and the trial management group are held by the NICTU.

The principal investigator or designee records all directly observed adverse events (AEs) and all AEs spontaneously reported by the patient. The principal investigator or designee assesses all AEs for seriousness, causality and severity, and if the $\mathrm{AE}$ is related to the study drug, for expectedness.

The AE reporting period for the participant begins upon enrolment into the trial and ends 30 days following the last administration of the study drug. All AEs are assessed by the principal investigator as possibly, probably or definitely related to the study drug and all serious adverse events (SAEs) that occur during this time will be followed until they are resolved or are clearly determined to be due to a patient's stable or chronic condition or intercurrent illness(es). Reporting follows the regulatory requirements and NICTU standard operating procedures.
For TRAC-24, a SAE is an AE that:

- results in death

- is life-threatening

- requires hospitalisation or prolongation of existing hospitalisation (even if only for 1 day)*

- results in persistent or significant disability or incapacity

- involves a congenital anomaly or birth defect

- is any other important medical events that carries a real, not hypothetical, risk of one of the outcomes above.

"Hospitalisation is defined as an inpatient admission regardless of length of stay, even if the hospitalisation is a precautionary measure for continued observation. Hospitalisations for a pre-existing condition, including elective procedures that have not worsened, do not constitute an SAE.

\section{Data collection and management}

An electronic CRF is used to collect the data for each study subject. Patient identification on the CRF is through their unique trial identifier, allocated at the time of recruitment. Data coding is carried out at various stages during the study. The electronic CRF is subject to audit by the sponsor. Data integrity and study credibility depend on factors such as ensuring adherence to the protocol and using quality control measures to establish and maintain high standards for data quality. To ensure accurate, complete and reliable data are collected, the NICTU provide training to site staff in the format of investigator meetings and/or site initiation visits. The data are validated and discrepancy reports are generated following data entry to identify discrepancies, such as out of range values, inconsistencies or protocol deviations based on data validation checks programmed into the clinical trial database. Data security and storage follows the data management plan specific to this study, NICTU standard operating procedures and the sponsor's requirements. The DMEC is convened to carry out reviews of the data at staged intervals during the study.

The dropout rate is expected to be negligible with little or no missing data for the primary outcome measure. Standard approaches will be used to detect patterns in missing data for the other outcomes.

\section{Statistical and interim analysis}

Based on a mean (standard deviation) of 1225 (499) mL of blood loss and a clinically significant difference of $150 \mathrm{~mL}$ (12\%) between the two TXA groups, originally the trial required 233 participants per group at $90 \%$ power and 0.05 level of significance. Due to the proven greater blood loss in control group 3, there were only half this number 
of participants in this group $(n=117)$. This would result in a total of 1166 participants (583 TKA and 583 THA), as a negligible dropout rate was expected. The clinically significant difference of $150 \mathrm{~mL}$ was based on an internal audit of blood loss in primary THA and TKA patients. The audit found that the average calculated blood loss was almost $1500 \mathrm{~mL}$. Based on this and the clinical opinion of the anaesthetists, surgeons, and haematologist involved in the study, a value of $150 \mathrm{~mL}$ (10\% of the average blood loss) was considered to be clinically significant.

Based on the strong rationale that TXA is effective at reducing blood loss for THA and TKA, a planned interim analysis was performed to compare the control and combined intervention groups to determine whether recruitment to control group 3 should continue. A power calculation determined that a sample size of 98 patients would be required to detect a clinically relevant difference of $450 \mathrm{~mL}$ of blood loss between the control and combined intervention groups at the significance level of $p=0.01$ and $90 \%$ power. The analysis was performed separately for THA and TKA participants and also for the combined participants.

Following this interim analysis, the DMEC recommended to the TSC that randomisation to control group 3 of patients recruited should be stopped. A minimum of 932 patients is required with an allocation of 466 (233 TKA and 233 THA) to intervention group 1 and 466 (233 TKA and 233 THA) to intervention group 2. Atogether, 134 patients were randomised to control group 3 . Eligible participants are now allocated to intervention group 1 or intervention group 2 with an allocation ratio of 1:1.

Analyses will be on an intention-to-treat basis and at an a priori significance level of $p=0.05$. Baseline characteristics and outcome measures will be summarised as mean and standard deviation, median and inter-quartile range or numbers and proportions (\%) depending on the scale of measurement. For the primary outcome and other continuous outcomes, analysis of variance with contrasts will be used to compare both intervention groups and also the intervention groups combined versus the control group. Analysis of covariance will be used to adjust for baseline and other covariates where appropriate. The chi-squared test will be used to test the difference in the proportions between the groups for the categorical variables. All analyses will be performed for THA and TKA separately and also combined. Subgroup analyses will be performed on the primary outcome measure for THA/TKA, creatinine, age, gender and body mass index. A statistical analysis plan will be written and approved prior to commencement of any analyses.

\section{Health economic analysis}

A cost analysis will be performed from a hospital perspective to compare the cost per patient in each treatment group. Data relating to patients' primary hospital admission is collected prospectively until primary hospital discharge (including but not limited to their length of stay on a ward and in the intensive care unit). Data relating to readmissions, accident and emergency attendances and outpatient attendances is collected at 90 days. Unit costs will be obtained from public sources, e.g. Department of Health reference costs. Differences in costs between groups will be estimated using regression methods adjusted for baseline and other covariates where appropriate.

\section{Discussion}

TXA is effective at reducing blood loss in elective joint arthroplasty. TRAC-24 extends administration of TXA to primary THA and TKA patients up to $24 \mathrm{~h}$ post-operatively with the aim of further reducing blood loss. The coagulation pathway for TXA is a system with a tightly controlled balance and theoretically TXA could act as a pro-coagulant and produce VTE. To date, there is no evidence to suggest it does. A Cochrane review in 2011 concluded that TXA did not increase the risk of death, myocardial infarction, cerebrovascular accident, deep vein thrombosis, pulmonary embolism or renal impairment [31]. In 2014, Poeran retrospectively analysed outcome data on 872,416 TKA or THA patients and found no increase in thromboembolic events nor renal impairment with TXA use [32]. However, all published randomised controlled trials to date have excluded patients with previous thromboembolic disease. The data are, thus, criticised for not reflecting a true safety profile. TRAC-24 is novel in that such patients are not excluded and thus, it is intended that this study will assist in defining the safety profile of TXA in primary joint arthroplasty for patients with a history of thromboembolic disease.

Since TRAC-24 commenced, there have been several challenges to overcome. Firstly, recruitment has taken longer than expected. This is primarily because of a reduction in the number of primary THA and TKA operations performed at the study site since the study was planned. In addition, there was a delay in starting the study and we have also found seasonal changes in recruitment due to, for example, a winter bed crisis that reduced the number of elective procedures performed. Additional funding was secured to enable the study to continue. In addition, there was difficulty in collecting some of the data for the exploratory outcomes at the 90-day time point. The protocol stated that participants would be contacted via telephone for this information; however, the information they provided was not always complete and participants did not always answer their telephone. To avoid important safety data being missing for the study, an amendment was approved allowing us to use the Northern Ireland Electronic Care Record to collect this data for all prospective participants and for all participants who had already been recruited, if their data could not be obtained using the original protocol. 
Originally, this study had been designed with three arms to include both interventions and also a control arm, which was standard care without TXA. The numbers allocated to each arm were in the ratio 2:2:1. It was felt necessary to include the no TXA arm, control group 3, because although TXA is known to reduce blood loss, it was not the standard of care in our unit. However, it was stipulated in the protocol that there must be an interim analysis once 100 THA and 100 TKA patients had been recruited to decide on the continuation of the control group 3 . At that time, 40 patients had been recruited into this group. Following this analysis, the DMEC recommended dropping control group 3, which was ratified by the TSC. This change was implemented following approvals from the sponsor, the research ethics committee and MHRA. This also resulted in a change in practice in our unit, with TXA being considered for all primary joint patients at the discretion of the anaesthetist.

The authors are aware of some limitations to this study. Firstly, it is a single-centre study; therefore, it could be argued that the results are not transferable to other centres due to different clinical practices. Secondly, randomisation is performed using sealed envelopes with tamper-proof labels instead of an automated system. While both systems were considered during the study design, it was decided that as it was a single-centre study with robust checks by the study site and by the NICTU, sealed envelopes were sufficient.

With TRAC-24, we intend to determine if the effect of TXA can be potentiated by continuing its administration post-operatively, at the time of greatest loss.

\section{Trial status}

Recruitment started in July 2016 and is ongoing at the time of manuscript submission. At the end of February 2018, 879 participants have been recruited to the study and protocol version 5 (8 November 2017) is currently in use. As with previous amendments, changes to the protocol and any related documents (e.g. the patient information sheet) require regulatory authority or ethics committee approval prior to implementation, except when modification is needed to eliminate an immediate hazard to patients. It is expected that the study will be fully recruited by July 2018 .

\section{Additional file}

Additional file 1: SPIRIT 2013 Checklist: Recommended items to address in a clinical trial protocol and related documents. (DOC $137 \mathrm{~kb}$ )

\section{Abbreviations}

AE: Adverse event; AR: Adverse reaction; BOIS: Belfast Orthopaedic Information System; Cl: Chief investigator; CREST: Clinical Resource Efficiency Support Team; CRF: Case report form; CRP: C-reactive protein; DMEC: Data monitoring and ethics committee; DOS: Day of surgery; Hb: Haemoglobin; Hct: Haematocrit; INR: International normalised ratio; IV: Intravenous;
KTS: Knife to skin; MHRA: Medicine and Healthcare Products Regulatory Agency; NICTU: Northern Ireland Clinical Trials Unit; OHS: Oxford hip score; OKS: Oxford knee score; PBV: Patient's blood volume; RBC: Red blood cell volume loss; SAE: Serious adverse event; THA: Total hip arthroplasty; TKA: Total knee arthroplasty; TSC: Trial steering committee; TXA: Tranexamic acid; VTE: Venous thromboembolism

\section{Acknowledgements}

The authors would like to acknowledge the Primary Joint Unit Patient Liaison Group, who assisted in the design of this study, and also the staff of Musgrave Park Hospital, who have supported this study and helped with the collection of data for TRAC-24.

\section{Funding}

This research is funded by the Belfast Arthroplasty Research Trust and the Health and Social Care Research and Development division of the Public Health Agency. This trial is being coordinated by the NICTU

(www.nictu.hscni.net). The trial complies with the principles of good clinical practice and is being carried out in accordance with applicable legislation and the standard operating procedures of the NICTU.

\section{Availability of data and materials}

Requests for data will be discussed on receipt of a formal request to the chief investigator. In the event of publications arising from such analyses, those responsible are required to provide the chief investigator with a copy of any intended manuscript for approval prior to submission and to discuss inclusion in authorship.

\section{Dissemination policy}

It is anticipated that the study findings will be published in national and international peer review journals and presented at national and international meetings and to appropriate patient groups, all of which will be led by the chief investigator. Upon request, participants may receive a lay summary of the principal study findings. The most significant results will be communicated to the public through press releases, and a paper on the primary outcome and safety data will be published soon after analysis and review. An ongoing update of the trial is maintained on the NICTU website.

\section{Study sponsor}

The TRAC-24 trial is sponsored by the Belfast Health and Social Care Trust, Northern Ireland. The sponsor has ultimate authority including indemnity, financial management and delegation of roles to the NICTU.

\section{Authors' contributions}

$J \mathrm{H}$ designed the study, developed the original protocol and subsequent amendments, and drafted the manuscript. PM contributed to protocol amendments and to drafting of the manuscript. AD and DB conceived the study, designed the study, developed the original protocol and subsequent amendments. $\mathrm{RH}, \mathrm{MMCF}$ and $\mathrm{EG}$ designed the study, developed the original protocol and subsequent amendments. AE designed the study, developed the original protocol and contributed to the drafting of the manuscript. GB and $L M$ designed the study and developed the original protocol. $L B, U M, C A$ JB, CC and GP contributed to protocol amendments. AA developed the original protocol and subsequent amendments. DM, BM and $\mathrm{SOH}$ contributed to the development of the original protocol. All authors read and approved the final manuscript.

Ethics approval and consent to participate

Ethical approval was granted for this clinical trial by East of England Cambridge East Research Ethics Committee (16/EE/0068). Clinical trial authorisation has been granted by the MHRA ( 32485/0030/001-0001). All participants gave written informed consent.

Consent for publication

Not applicable.

Competing interests

The authors declare that they have no competing interests. 


\section{Publisher's Note}

Springer Nature remains neutral with regard to jurisdictional claims in published maps and institutional affiliations.

\section{Author details}

'Primary Joint Unit, Musgrave Park Hospital, Belfast Health and Social Care Trust, Stockman's Lane, Belfast BT9 7JB, UK. ${ }^{2}$ Theatres, Musgrave Park Hospital, Belfast Health and Social Care Trust, Stockman's Lane, Stockman's Lane, Belfast BT9 7JB, UK. ${ }^{3}$ Department of Anaesthesia, Ulster Hospital, Upper Newtownards Road, Dundonald, Belfast BT16 1RH, UK. ${ }^{4}$ Department of Haematology, Tower block, Belfast City Hospital, Belfast Health and Social Care Trust, 51 Lisburn Road, Belfast BT9 7AB, UK. ${ }^{5}$ Pharmacy Department, The Royal Hospitals, Belfast Health and Social Care Trust Grosvenor Road, Belfast BT12 6BA, UK. ${ }^{6}$ Northern Ireland Clinical Trials Unit (NICTU), The Royal Hospitals, 1st Floor Elliott Dynes Building, Grosvenor Road, Belfast BT12 6BA UK.

Received: 30 March 2018 Accepted: 4 July 2018

Published online: 31 July 2018

\section{References}

1. Mannucci PM, Levi M. Prevention and treatment of major blood loss. N Engl J Med. 2007;356:2301-11.

2. Sehat KR, Evans RL, Newman JH. Hidden blood loss following hip and knee arthroplasty. Correct management of blood loss should take hidden loss into account. J Bone Joint Surg Br. 2004:86:561-5.

3. Chen Y, Chen Z, Cui S, Li Z, Yuan Z. Topical versus systemic tranexamic acid after total knee and hip arthroplasty: a meta-analysis of randomized controlled trials. Medicine (Baltimore). 2016;95:e4656.

4. Ker K, Edwards P, Perel P, Shakur H, Roberts I. Effect of tranexamic acid on surgical bleeding: systematic review and cumulative meta-analysis. BMJ. 2012;344:e3054.

5. Rossaint R, Bouillon B, Cerny V, Coats TJ, Duranteau J, FernandezMondejar $E_{\text {, et }}$ al. The European guideline on management of major bleeding and coagulopathy following trauma: fourth edition. Crit Care. 2016;20:100. 016-1265-x

6. Roberts I, Shakur H, Coats T, Hunt B, Balogun E, Barnetson L, et al. The CRASH-2 trial: a randomised controlled trial and economic evaluation of the effects of tranexamic acid on death, vascular occlusive events and transfusion requirement in bleeding trauma patients. Health Technol Assess. 2013;17:1-79.

7. Sukeik M, Alshryda S, Haddad FS, Mason JM. Systematic review and metaanalysis of the use of tranexamic acid in total hip replacement. J Bone Joint Surg Br. 2011;93:39-46.

8. Tan J, Chen H, Liu Q, Chen C, Huang W. A meta-analysis of the effectiveness and safety of using tranexamic acid in primary unilateral total knee arthroplasty. J Surg Res. 2013;184:880-7.

9. Goobie SM. Tranexamic acid: still far to go. Br J Anaesthesia. 2017:118(3):293-5.

10. Su EP, Su S. Strategies for reducing peri-operative blood loss in total knee arthroplasty. Bone Joint J. 2016;98-B:98-100.

11. Gillette BP, DeSimone LJ, Trousdale RT, Pagnano MW, Sierra RJ. Low risk of thromboembolic complications with tranexamic acid after primary total hip and knee arthroplasty. Clin Orthop Relat Res. 2013;471:150-4.

12. Heller S, Secrist E, Shahi A, Chen AF, Parvizi J. Tranexamic acid can be administered to arthroplasty patients who receive aspirin for venous thromboembolic prophylaxis. J Arthroplast. 2016;31:1437-41.

13. Walterscheid Z, O'Neill C, Caramouche J. Tranexamic acid in adult elective orthopaedic and complex spinal surgery: a review. Surg Rehabil. 2017;1:1-4.

14. Zhang $P$, Liang $Y$, Chen $P$, Fang $Y$, He J, Wang J. Intravenous versus topical tranexamic acid in primary total hip replacement: a meta-analysis. Medicine (Baltimore). 2016;95:e5573.

15. Maniar RN, Kumar G, Singhi T, Nayak RM, Maniar PR. Most effective regimen of tranexamic acid in knee arthroplasty: a prospective randomized controlled study in 240 patients. Clin Orthop Relat Res. 2012;470:2605-12.

16. Molloy DO, Archbold HA, Ogonda L, McConway J, Wilson RK, Beverland DE. Comparison of topical fibrin spray and tranexamic acid on blood loss after total knee replacement: a prospective, randomised controlled trial. J Bone Joint Surg Br. 2007;89:306-9.

17. Xie J, Ma J, Yao H, Yue C, Pei F. Multiple boluses of intravenous tranexamic acid to reduce hidden blood loss after primary Total knee arthroplasty without tourniquet: a randomized clinical trial. J Arthroplast. 2016;31:2458-64.
18. Machin JT, Batta V, Soler JA, Sivagaganam K, Kalairajah Y. Comparison of intra-operative regimes of tranexamic acid administration in primary total hip replacement. Acta Orthop Belg. 2014;80:228-33.

19. Themistoklis T, Theodosia V, Konstantinos K, Georgios DI. Perioperative blood management strategies for patients undergoing total knee replacement: where do we stand now? World J Orthop. 2017:8:441-54.

20. Nadler SB, Hidalgo JH, Bloch T. Prediction of blood volume in normal human adults. Surgery. 1962;51:224-32.

21. Mercuriali F, Inghilleri G. Proposal of an algorithm to help the choice of the best transfusion strategy. Curr Med Res Opin. 1996;13:465-78.

22. Yamasaki S, Masuhara K, Fuji T. Tranexamic acid reduces postoperative blood loss in cementless total hip arthroplasty. J Bone Joint Surg Am. 2005:87:766-70.

23. Tanaka N, Sakahashi H, Sato E, Hirose K, Ishima T, Ishii S. Timing of the administration of tranexamic acid for maximum reduction in blood loss in arthroplasty of the knee. J Bone Joint Surg Br. 2001;83:702-5.

24. Zohar E, Ellis M, Ifrach N, Stern A, Sapir O, Fredman B. The postoperative blood-sparing efficacy of oral versus intravenous tranexamic acid after total knee replacement. Anesth Analg. 2004;99:1679-83.

25. Miao K, Ni S, Zhou X, Xu N, Sun R, Zhuang C, et al. Hidden blood loss and its influential factors after total hip arthroplasty. J Orthop Surg Res. 2015;10:36.

26. Jansen AJ, Andreica S, Claeys M, D'Haese J, Camu F, Jochmans K. Use of tranexamic acid for an effective blood conservation strategy after total knee arthroplasty. Br J Anaesth. 1999;83:596-601.

27. Lee QJ, Chang WY, Wong YC. Blood-sparing efficacy of oral tranexamic acid in primary Total hip arthroplasty. J Arthroplast. 2017;32:139-42.

28. Luo ZY, Wang HY, Wang D, Zhou K, Pei FX, Zhou ZK. Oral vs intravenous vs topical tranexamic acid in primary hip arthroplasty: a prospective, randomized, double-blind, controlled study. J Arthroplast. 2018;33:786-93.

29. Gross JB. Estimating allowable blood loss: corrected for dilution. Anesthesiology. 1983;58:277-80.

30. Murray DW, Fitzpatrick R, Rogers K, Pandit H, Beard DJ, Carr AJ, et al. The use of the Oxford hip and knee scores. J Bone Joint Surg Br. 2007:89:1010-4.

31. Henry DA, Carless PA, Moxey AJ, O'Connell D, Stokes BJ, Fergusson DA, et al. Anti-fibrinolytic use for minimising perioperative allogeneic blood transfusion. Cochrane Database Syst Rev. 2011;(1):CD001886.

32. Poeran J, Rasul R, Suzuki S, Danninger T, Mazumdar M, Opperer M, et al. Tranexamic acid use and postoperative outcomes in patients undergoing total hip or knee arthroplasty in the United States: retrospective analysis of effectiveness and safety. BMJ. 2014;349:94829.

Ready to submit your research? Choose BMC and benefit from:

- fast, convenient online submission

- thorough peer review by experienced researchers in your field

- rapid publication on acceptance

- support for research data, including large and complex data types

- gold Open Access which fosters wider collaboration and increased citations

- maximum visibility for your research: over $100 \mathrm{M}$ website views per year

At BMC, research is always in progress.

Learn more biomedcentral.com/submissions 